\title{
Autonomic thermoregulatory dysfunction in neurofibromatosis type 1
}

\author{
Disfunção autonômica termorregulatória na neurofibromatose do tipo 1 \\ Luciana G Madeira17, Renata LF Passos', Juliana F de Souza², Nilton A Rezende², Luiz O. C. Rodrigues ${ }^{1,2}$
}

\begin{abstract}
Objective: Neurofibromatosis type 1 (NF1) causes neural and cutaneous disorders and reduced exercise capacity. Exercise/heat exposure increasing internal temperature must be compensated by eccrine sweat function and warmed skin vasodilation. We suspected NF1 could adversely affect eccrine sweat function and/or vascular thermoregulatory responses (VTR). Methods: The eccrine sweat function and VTR of 25 NF1 volunteers (14 males, 11 females; 16-57 years old) were compared with 23 non-NF1 controls matched by sex, age, height and weight (CG). Sweating was induced by 1) pilocarpine 1\% iontophoresis (PILO); and 2) by passive heating (HEAT) via the lower third of the legs being immersed in $42^{\circ} \mathrm{C}$ water for one hour. Previously established eccrine sweat function and VTR protocols were used. Results: The NF1 group showed: a) lower sweat rate than the CG group during PILO; b) a smaller diastolic pressure decrease; and c) higher tympanic temperatures than controls during HEAT $(p<0.05)$. Conclusion: Reduced sweating and vascular thermoregulatory responses suggest autonomic dysfunction in NF1 individuals.
\end{abstract}

Keywords: neurofibromatosis 1; sweating; primary dysautonomias; body temperature regulation.

\section{RESUMO}

Objetivo: Neurofibromatose do tipo 1 (NF1) causa problemas neurais e cutâneos e diminuição da capacidade física. 0 aumento da temperatura interna durante exercício e exposição ao calor precisa ser compensada pela função sudorípara écrina (FSE) e aquecimento cutâneo por vasodilatação (RVT). Suspeitou-se clinicamente que a NF1 poderia prejudicar a FSE e a RVT. Métodos: A FSE e RVT de 25 voluntários com NF1 (14 homens, 11 mulheres; 16-57 anos) e de 23 sem-NF1, emparelhados por sexo, idade, estatura e peso corporal, foram medidas com protocolos validados anteriormente. A sudorese foi induzida por iontoforese com pilocarpina (PILO) e aquecimento passivo por imersão das pernas em água a $42^{\circ} \mathrm{C}$ durante uma hora (HEAT). Resultados: 0 grupo NF1 apresentou menor taxa de sudorese na situação PILO, menor redução da pressão diastólica e maior temperatura timpânica na situação HEAT ( $p<0.05)$. Conclusão: As respostas sudorípara e vascular reduzidas sugerem disfunção autonômica nas pessoas com NF1.

Palavras-chave: neurofibromatose 1; sudorese; disautonomia primária; regulação da temperatura corporal.

Neurofibromatosis type 1 (NF1) is an autosomal dominant disorder, caused by mutations in a single gene (OMIM \#162200, neurofibromin, 17 q11.2) affecting the development-maintenance-repair of neural and cutaneous tissues. Neurofibromatosis type 1 is the most common human monogenetic disease (1:3000, affecting nearly 80,000 Brazilian people) and it exhibits marked phenotype expression variability and an unpredictable course $\mathrm{e}^{1,2,3}$.

Recently, we described decreased muscular strength ${ }^{4}$ and lower aerobic capacity in NF1 individuals ${ }^{5}$, and both features are related to life expectancy, and quality of life. Possible mechanisms involving NF1-reduced muscle strength and aerobic capacity could be neurological abnormalities related to the neurofibromin deficiency, such as poorer motor coordination/activation, as well as lower levels of daily physical activities and motivation for exercising. Both neural disorder and reduced aerobic capacity could adversely affect thermoregulatory capacity, leading to decreased exercise performance in hot environments and heat intolerance with higher risk for heat-related injuries ${ }^{6}$.

Despite increases in environmental temperature and/or exercise body metabolism, human internal temperature must be maintained within a small physiological range through heat dissipation, to prevent tissue

${ }^{1}$ Universidade Federal de Minas Gerais, Escola de Educação Física, Fisioterapia e Terapia Ocupacional, Programa de Pós Graduação em Ciências do Esporte, Belo Horizonte MG, Brasil;

${ }^{2}$ Universidade Federal de Minas Gerais, Hospital das Clínicas, Centro de Referência em Neurofibromatoses, Belo Horizonte MG, Brasil.

Correspondence: Luiz O. C. Rodrigues; R. RL Aroeira, 40; 31710-570vBelo Horizonte MG, Brasil; E-mail: rodrigues.loc@gmail.com

Support: CNPq, FAPEMIG, CAPES, UFMG

Conflict of interest: There is no conflict of interest to declare.

Received 27 April 2016; Received in final form 08 June 2016; Accepted 20 June 2016. 
damage, especially in the brain ${ }^{7}$. The main human physiological mechanisms to dissipate metabolic heat consist of increased skin temperature, through cutaneous vasodilation and sweat production and vaporization, both simultaneously triggered by increased internal and skin temperatures. Individual characteristics may affect the magnitude of thermoregulatory responses, including sex, aerobic capacity, as well as the existence of any disease ${ }^{6,8,9}$.

As an example, the neuropathy caused by progressive central demyelization in multiple sclerosis produces systemic failure in maintaining internal temperature during heat exposure due to decreased neural control of cardiovascular responses and impaired sweat function. As a result, most multiple sclerosis patients experience transient and temporary worsening of clinical signs and neurological symptoms during exposure to higher environmental temperatures and exercise $^{10}$. Additionally, exercise intolerance and sweating dysfunction are considered common manifestations of diabetic autonomic neuropathy, even in the early stages of this disease, once the sweating response is diminished or completely suppressed, especially in lower limbs ${ }^{11,12}$.

Neuropathy in NF1 patients has been related to nerve compression and/or loss of function by the growth of neurofibromas, or to inappropriate genetic signaling between neural cells, and it is considered to be a benign condition. Polyneuropathies and neurofibromatous neuropathy have been rarely reported in $1.3 \%$ to $6 \%$ of NF1 patients, depending on the investigational methods applied ${ }^{13,14,15}$. However, to the best of our knowledge, central and peripheral thermoregulatory responses to heat stress have not been studied in NF1. Moreover, the reduced exercise functional capacity $^{5}$ together with heat intolerance complaints in our clinical observations led us to hypothesize a thermoregulatory dysfunction in NF1 patients.

Therefore, the aim of this study was to compare autonomic thermoregulatory responses of NF1 individuals with non-NF1 controls matched by sex, age, height and weight.

\section{METHODS}

We assessed 14 males and 11 females with NF1 (NF1 group), from 16 to 57 years of age, selected among patients of the Neurofibromatosis Outpatient Reference Center. They met at least three NF1 diagnostic criteria (National Institutes of Health Consensus Development Conference, 1988). The control group (CG) comprised 23 non-NF1 individuals (12 males and 11 females) matched by sex, age, and anthropometric features to the NF1 group.

These experiments were conducted between February 2013 and February 2014. The Research Ethics Committee of the Universidade Federal de Minas Gerais approved this study and the procedures were performed according to the norms of Resolution 196 of the Brazilian National Health
Council (1996) on scientific research involving humans. All volunteers provided written informed consent prior to participating in the trials.

The sweating responses were induced twice: by local stimuli via administration of pilocarpine 1\% (PILO) using a previously validated protocol9, and by central stimuli, through a passive heating protocol (HEAT). In both situations, volunteers remained seated during all tests after anthropometric (body weight, height, and body surface area) and hydration status (urine specific gravity) evaluations were performed. Additionally, tympanic temperature (Tty) and skin temperatures (Tsk) were monitored every 15 and 2 minutes, respectively, by specific infrared thermometers (G-TECH ${ }^{\circ}$ IR1DB1, Brazil and FLUKE 566, Brazil).

At first, sweat secretion was locally induced at the proximal anterior face of the right forearm by local administration of pilocarpine hydrochloride (4 mL; 1\%) using iontophoresis (1.5 mA, $\left.60 \mu \mathrm{A} . \mathrm{cm}^{-2}, 5 \mathrm{~min}\right)$, under neutral environmental temperature conditions $\left(\sim 24^{\circ} \mathrm{C}\right)$. To prevent individual variations in local skin temperature, the forearm was heated for 15 minutes prior to pharmacological stimulation and its temperature was maintained $\left(\sim 35^{\circ} \mathrm{C}\right)$ throughout the experiment, using radiant heat from an adjustable infrared emission lamp (Quartz ${ }^{\circ}$, Brazil). It has been shown previously that these procedures induce maximal sweating to pilocarpine, irrespective of sex and aerobic capacity?.

Sweat secretion was collected for 15 minutes just after stimulation using a $16 \mathrm{~cm}^{2}$ absorbent paper (J Prolab, Brazil) placed inside a plastic chamber to prevent sweat evaporation. Active sweat glands (ASG) were printed using the iodine impregnated paper technique, and quantified (gland. $\mathrm{cm}^{-1}$ ) via digital processing using a free computer program (ImageJ) as previously described ${ }^{15}$. The local sweat rate (SR) was determined based on differences in weight of the absorbent paper before and after sweat collection (Mettler Toledo AB 204 analytical scale, USA) divided by its area and time of collection. Finally, sweat gland output (SGO) was calculated by dividing SR by ASG.

Secondly, approximately six months after the first test, volunteers were passively heated through lower-leg immersion $(30 \mathrm{~cm})$ in hot water $\left(42^{\circ} \mathrm{C}\right)$ for 60 minutes. The environmental air temperature was maintained between $28^{\circ} \mathrm{C}$ and $30^{\circ} \mathrm{C}$. Collection of sweat (throughout the experiment) and ASG imprints were obtained in the same region of the right forearm, as described above. Sweat and ASG imprints were also collected from the right upper-chest, right upper-back and anterior right mid-thigh. Temperatures (Tty and Tsk on each of the four areas described above), sweating (SR, SGO) and heat storage rates were also recorded. Heart rate and arterial blood pressure (systolic, diastolic and mean blood pressures) were continuously monitored using a cardiofrequencimeter (Polar ${ }^{\circ}$ Vantage NV) and an arterial tonometer (Colin ${ }^{\circ}$ 2000, Texas) respectively. 


\section{Statistical analysis}

In the PILO experiments, the Student's t-test was used to assess differences between the groups in physical characteristics, SR, ASG, and SGO, and one-way ANOVA with repeated measures was used to evaluate differences between groups, and over time, in Tty and Tsk. In the HEAT experiments, SR, ASG and SGO differences were assessed using two-way ANOVA, with the groups and body areas as factors.

During the entire duration of the HEAT experiments, one-way ANOVA or two-way ANOVA with repeated measures was used to compare Tty among groups and Tsk, heart rate and arterial pressure parameters between the groups and body areas, respectively. ANOVA analysis was followed by Fisher's least-significant difference post-hoc test when applicable. Finally, physical characteristics, in both experiments, and heat storage rate in HEAT, were evaluated with the Student's t-test. Significance was established at $\alpha=0.05$ and results are presented as mean \pm standard deviation.

\section{RESULTS}

Physical characteristics of males and females in the NF1 and CG groups are shown in Table 1. The NF1 and CG were successfully matched and there were no differences between them in age, height, weight or body surface area. However, both NF1 and control group men were taller, heavier and presented a bigger body surface area than women, as expected.
The NF1 volunteers presented with reduced sweating responses to local pharmacological stimulation (Figure 1). Both SR (males: NF1 $=0.42 \pm 0.16$ vs. $\mathrm{CG}=0.71 \pm 0.31$; females: $\mathrm{NF} 1=0.28 \pm 0.12$ vs. $\left.\mathrm{CG}=0.63 \pm 0.16 \mathrm{mg} \cdot \mathrm{cm}^{-2} \cdot \mathrm{min}^{-1}, \mathrm{p}<0.05\right)$ and SGO (males: $\mathrm{NF} 1=4.68 \pm 1.20$ vs. $\mathrm{CG}=7.60 \pm 2.86$; females: $\mathrm{NF} 1=2.75 \pm 0.98$ vs. $\mathrm{CG}=5.11 \pm 1.62 \mu$ g.gland $\left.{ }^{-1} \cdot \mathrm{min}^{-1}, \mathrm{p}<0.05\right)$ were reduced in the NF1 group when compared to the $\mathrm{CG}$, irrespective of sex. Nevertheless, the number of ASG was reduced only among women in the NF1 group compared to the CG (females: NF1 = $98 \pm 21$ vs. CG $=129 \pm 33$ glands.cm ${ }^{-2}$, $\mathrm{p}<0.05)$. The typical differences in sweating between sexes was also observed: men displayed higher SGO and lower ASG than women $(\mathrm{p}<0.05)$.

The PILO phase of the study was designed to prevent influences of core, skin and environmental temperatures on sweating. This objective was attained once there were non-significant variations of core (tympanic range: $37.17 \pm 0.35$ to $37.34 \pm 0.66^{\circ} \mathrm{C} ; \mathrm{p}>0.05$ ), local skin ( forearm range: $34.39 \pm 0.25$ to $34.47 \pm 0.6^{\circ} \mathrm{C} ; \mathrm{p}>0.05$ ), and environmental temperatures (air range: $23.86 \pm 0.39 \mathrm{C}$ to $\left.24.20 \pm 0.58^{\circ} \mathrm{C} ; \mathrm{p}>0.05\right)$.

During central stimulation via passive heating (HEAT), the NF1 group sweat secretion was also reduced (Figure 2). The NF1 sub-groups showed lower SR in every region measured: (males: forearm $=0.18 \pm 0.07$; chest $=0.25 \pm 0.09$; back $=0.31 \pm 0.15$; thigh $=0.09 \pm 0.05$; and females: forearm $=0.12 \pm 0.01$; chest $=0.23 \pm 0.13$; back $=0.27 \pm 0.14$; thigh $=0.07 \pm 0.05$ ) when compared to the CG sub-groups (males: forearm $=0.26 \pm 0.07$; chest $=0.46 \pm 0.21$; back $=0.49 \pm 0.23$; thigh $=0.14 \pm 0.04$; and

Table 1. Physical characteristics (Mean \pm SD).

\begin{tabular}{lcccc} 
Variable & Age (years) & Height $(\mathrm{m})$ & Weight $(\mathrm{kg})$ & BSA $\left(\mathrm{m}^{2}\right)$ \\
\hline GC male & $39 \pm 14$ & $1.69 \pm 0.06$ & $75.89 \pm 16.42$ & $1.85 \pm 0.20$ \\
NF1 male & $36 \pm 12$ & $1.70 \pm 0.06$ & $74.07 \pm 19.33$ & $1.84 \pm 0.21$ \\
GC female & $33 \pm 6$ & $1.58 \pm 0.07^{\#}$ & $53.56 \pm 3.84^{\#}$ & $1.53 \pm 0.10^{\#}$ \\
NF1 female & $33 \pm 9$ & $1.55 \pm 0.09^{\#}$ & $56.10 \pm 9.12^{\#}$ & $1.54 \pm 0.16^{\#}$ \\
\hline
\end{tabular}

SD:standard deviation;BSA: body surface area; CG: non-NF1 control group;NF1: neurofibromatosis type 1 individuals; \# Difference between males and females.

A

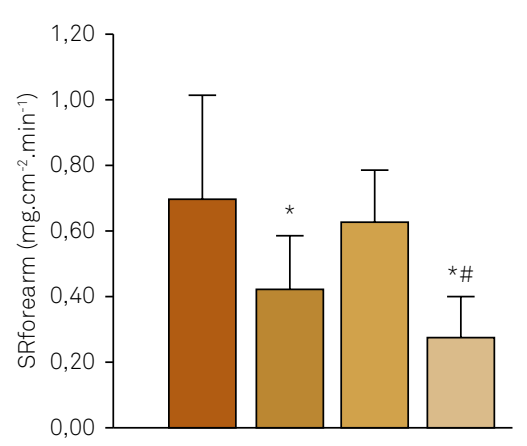

B

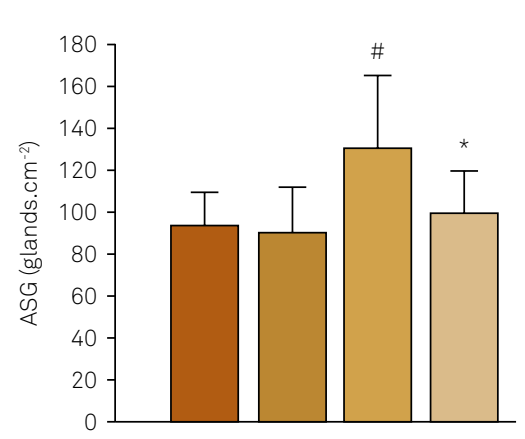

C

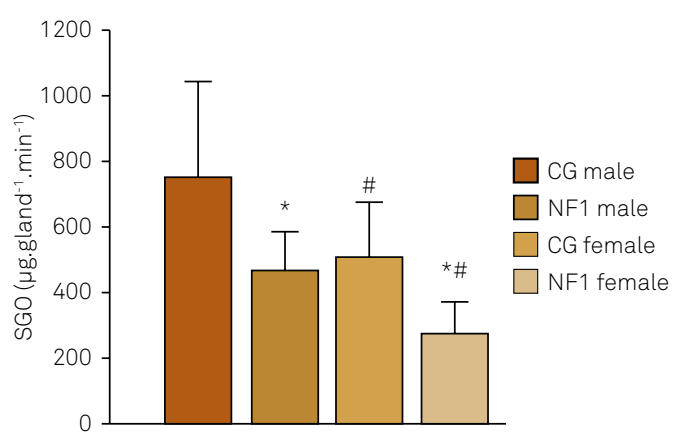

Mean \pm SD. (A) Local sweat rate (SR); (B) Number of active sweat glands (ASG); (C) sweat gland output (SGO). SD: standard deviation; CG: control group; NF1: neurofibromatosis type 1. *Difference between NF1 and GC; "Difference between males and females.

Figure 1. Sweating responses in PILO. 
females:forearm $=0.20 \pm 0.06$; chest $=0.38 \pm 0.18$; back $=0.47 \pm 0.18$; thigh $\left.=0.17 \pm 0.06 \mathrm{mg} \cdot \mathrm{m}^{-2} \cdot \mathrm{min}^{-1} ; \mathrm{p}<0.05\right)$. Similarly, the SGO was significantly reduced in the NF1 group when compared to controls in almost every region (except the back), but only in female groups (NF1: forearm $=1.01 \pm 0.64$; chest $=3.09 \pm 1.64$; back $=5.18 \pm 2.87$; thigh $=0.74 \pm 0.63 \nu$ vs. CG: forearm $=1.89 \pm 0.69$; chest $=5.44 \pm 3.11$; back $=3.27 \pm 1.81$; thigh $=1.86 \pm 0.68 \mu$ g.gland $\left.{ }^{-1} \cdot \mathrm{min}^{-1} ; \mathrm{p}<0.05\right)$. Lastly, ASG was lower only in the back region between females NF1 ( $77 \pm 16$; $54 \pm 1)$ and $C G\left(70 \pm 22 ; 98 \pm 25\right.$ glands. $\left.m^{-2}\right)(p<0.05)$.

Heat storage rate was expressively higher in the NF1 group (males: $3212 \pm 236$; females: $2,065 \pm 230 \mathrm{~J} \cdot \mathrm{min}^{-1} \cdot \mathrm{m}^{2}$ ) than in controls (males: $93 \pm 1,171$; females: $559 \pm 1,198 \mathrm{~J} \cdot \mathrm{min}^{-1} \cdot \mathrm{m}^{2}$; $\mathrm{p}<0.05$ ) and, as a consequence, NF1 patient tympanic temperatures showed a larger increase than controls, becoming higher in NF1 groups at the end of the test (Figure 3; males: $\mathrm{NF} 1=38.5 \pm 0.4^{\circ} \mathrm{C}$ vs. $\mathrm{CG}=38.0 \pm 0.2^{\circ} \mathrm{C}$ and females: $\mathrm{NF} 1=38.5 \pm 0.4$ vs. $\mathrm{CG}=38.1 \pm 0.2^{\circ} \mathrm{C} ; \mathrm{p}<0.05$ ). In contrast, skin temperatures decreased in a similar way during the experiment in all groups and in every body region measured (Tskin initial range: $33.30 \pm 0.87^{\circ} \mathrm{C}$ to $35.01 \pm 0.40^{\circ} \mathrm{C}$ and Tsk final range: $32.80 \pm 1.3^{\circ} \mathrm{C}$ to $33.72 \pm 0.90^{\circ} \mathrm{C} ; \mathrm{p}>0.05$ ).

Table 2 shows the NF1 and control groups' cardiovascular responses to passive heating. In both NF1 and control groups, the heart rate increased, and systolic blood pressure remained stable throughout the test. Nevertheless, while heart rate and systolic blood pressure behaviors were not different between groups, the NF1 group's diastolic blood pressure and mean blood pressure did not display the expected decrease in those variables, resulting in higher end values in the NF1 group (males: $-1.69 \pm 4.29$; females: $-0.80 \pm 3.77 \mathrm{mmHg}$ ) when compared to controls (males: $-6.73 \pm 4.43$; females: $-7.50 \pm 4.64$ mmHg; $\mathrm{p}<0.05$ ).

\section{DISCUSSION}

The present study has identified markedly reduced thermoregulatory capacity in NF1 patients, which could contribute to their reduced aerobic capacity and daily physical activities as well as increasing their risk of heat injury and illnesses. These results suggest an autonomic neuropathy as the maim mechanism for reduced heat and exercise tolerance in NF1 patients.

Volunteers with NF1, irrespective of sex, showed lower sweat production both after local pharmacological stimulation and after central sweat induction by passive heating when compared to non-NF1 controls matched by age and anthropometric characteristics. The present study is the first to describe decreased thermoregulatory responses in NF1.

Impairments in the SR to local and/or central stimuli has already been reported in other diseases affecting the neural tissues, such as diabetes ${ }^{11,12,16}$, tuberous sclerosis ${ }^{17,18}$, multiple sclerosis $^{19}$, and leprosy ${ }^{20}$.
A
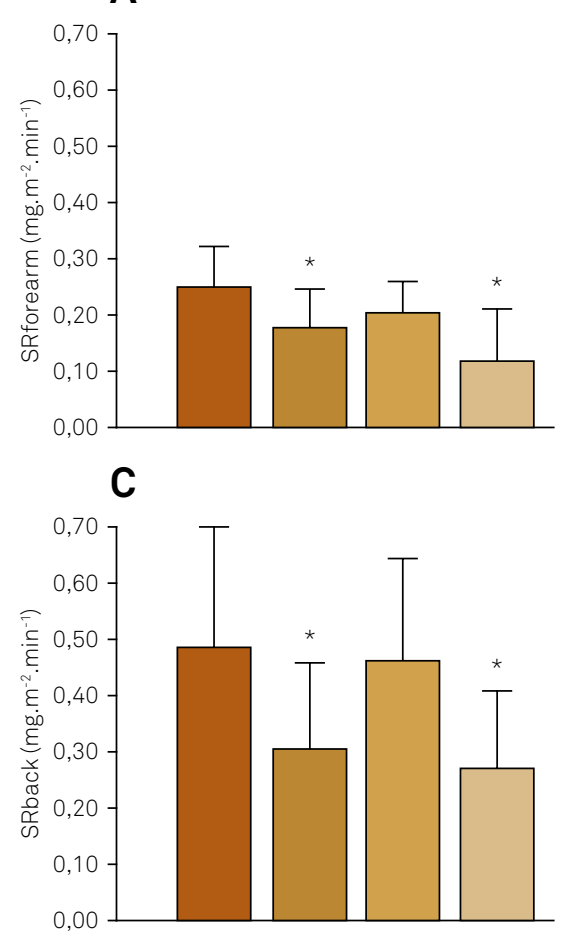

B
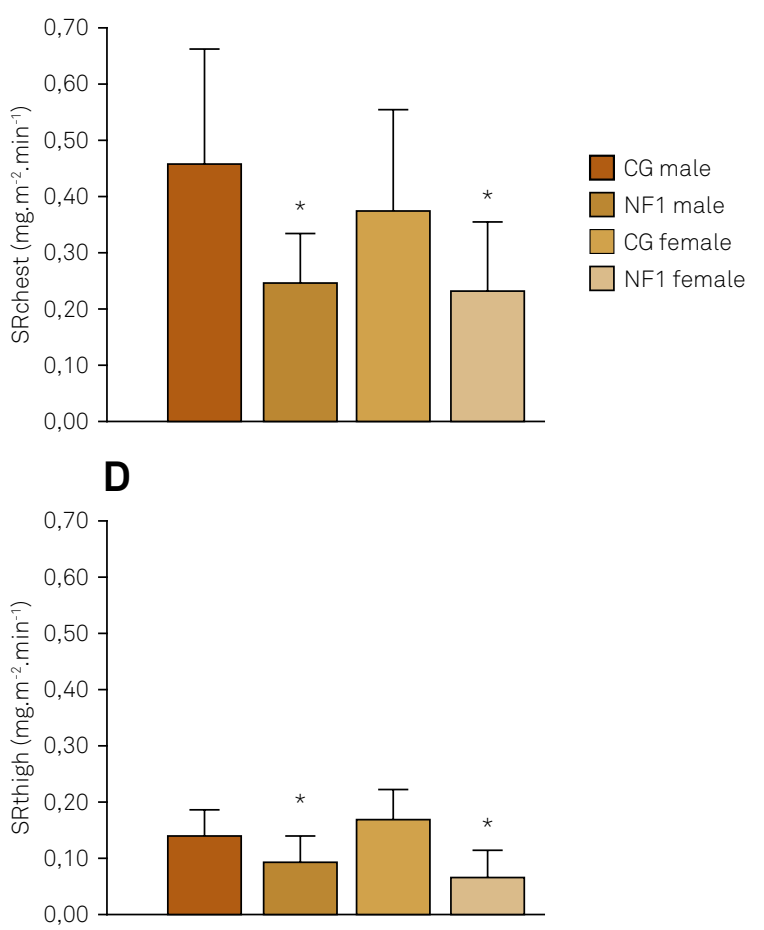

Mean \pm SD. Local sweat rate (SR) measured in forearm (A); chest (B); back (C) and thigh (D) during HEAT. SD: standard deviation; CG: control group; NF1: neurofibromatosis type 1; *Difference between NF1 and GC.

Figure 2. Sweating responses in HEAT. 


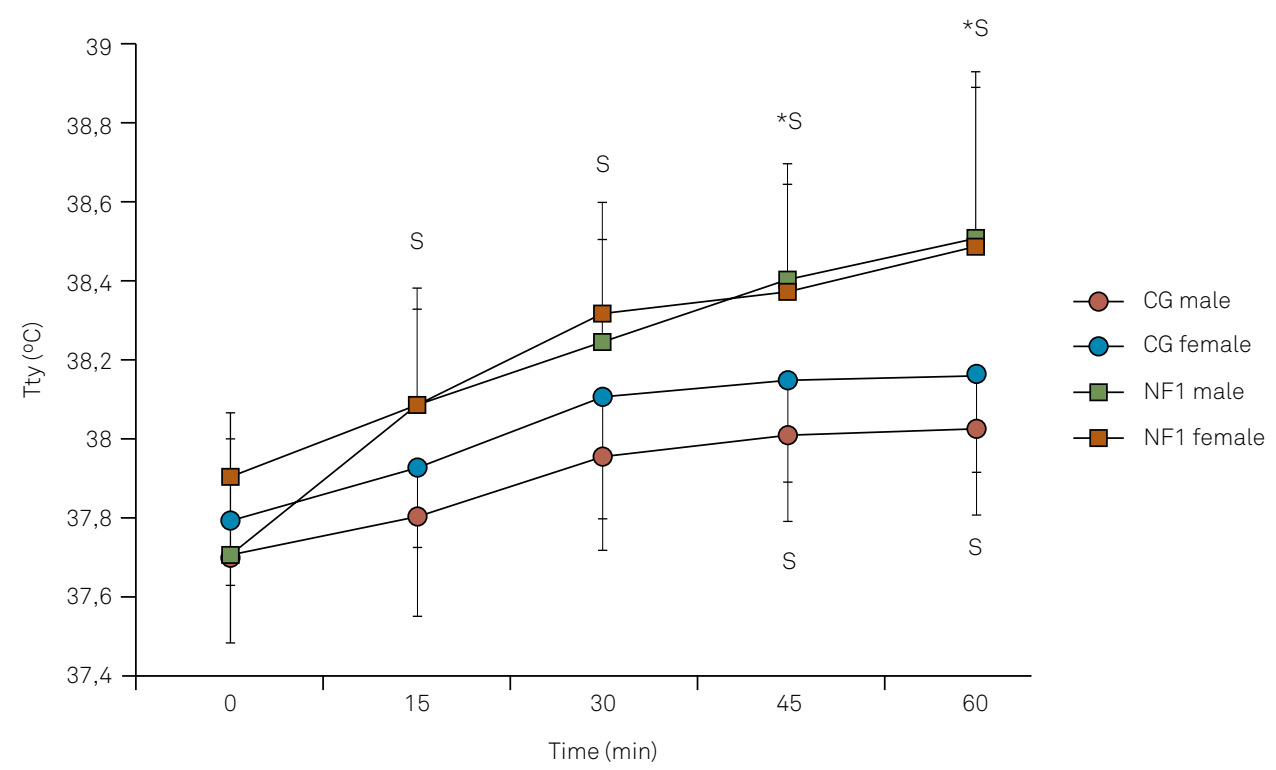

Mean \pm SD. Tympanic temperature (Tty) during HEAT. SD: standard deviation; CG: control group; NF1: neurofibromatosis type 1. *Difference between NF1 and GC; ${ }^{\$}$ Difference from initial values (minute 0).

Figure 3. Core Temperature in HEAT.

Table 2. Cardiovascular responses in HEAT experiments (Mean \pm SD).

\begin{tabular}{|c|c|c|c|c|c|c|c|c|}
\hline \multirow{2}{*}{ Group } & \multicolumn{2}{|c|}{ HR (bpm) } & \multicolumn{2}{|c|}{$\mathrm{SBP}(\mathrm{mmHg})$} & \multicolumn{2}{|c|}{$\mathrm{DBP}(\mathrm{mmHg})$} & \multicolumn{2}{|c|}{$\mathrm{MBP}(\mathrm{mmHg})$} \\
\hline & Initial & Final & Initial & Final & Initial & Final & Initial & Final \\
\hline CG male & $83 \pm 11$ & $93 \pm 12^{\$}$ & $112 \pm 11$ & $112 \pm 10$ & $66 \pm 6$ & $58 \pm 6^{\$}$ & $81 \pm 7$ & $76 \pm 7^{\$}$ \\
\hline NF1 male & $82 \pm 8$ & $94 \pm 13^{\$}$ & $120 \pm 9 *$ & $121 \pm 9 *$ & $71 \pm 7$ & $69 \pm 8^{\star}$ & $87 \pm 8 *$ & $86 \pm 8^{*}$ \\
\hline CG female & $78 \pm 11$ & $90 \pm 15^{\$}$ & $98 \pm 6^{\#}$ & $98 \pm 6^{\#}$ & $59 \pm 5^{\#}$ & $51 \pm 5^{\# \$}$ & $73 \pm 5^{\#}$ & $67 \pm 5^{\# \$}$ \\
\hline NF1 female & $79 \pm 8$ & $99 \pm 12^{\$}$ & $107 \pm 7$ \# & $108 \pm 8 * \#$ & $63 \pm 6^{\#}$ & $62 \pm 5^{\star \#}$ & $77 \pm 6^{\#}$ & $77 \pm 6$ *\# \\
\hline
\end{tabular}

SD: standard deviation; HR: heart rate; SBP: systolic blood pressure; DBP: diastolic blood pressure; MBP: mean blood pressure; NF1: neurofibromatosis type 1 individuals; CG: non-NF1 control group; *Difference between NF1 and GC; \#Difference between males and females. ${ }^{\$}$ Difference from initial values (minute 0).

The present results showed reduction of $35 \%$ to $65 \%$ in sweat secretion (induced by PILO and HEAT protocols) among NF1 volunteers compared to non-NF1 individuals. In the PILO tests, the reduction was associated with a decrease in sweating production (SGO $=-39 \%$ ) shown by NF1 males, and with a decrease in both SGO (-47\%) and number of active sweat glands $(\mathrm{ASG}=-34 \%)$ presented by NF1 females. However, during HEAT, only NF1 females displayed lower SGO when compared with CG females. Therefore, it is not possible to conclude if the lower NF1 male SR is related to reduced ASG, SGO, or both.

Pilocarpine stimulation of eccrine sweat glands is produced by direct binding of the cholinergic agonist to the muscarinic receptors on the gland, independent of sympathetic drive $^{21}$. Therefore, it is possible that the NF1-reduced sweat response elicited by the present method reflects disturbances in glands per se, specifically in their morphology (i.e. dystrophic or atrophic changes) and/or in their cholinergic sensitivity. Nevertheless, some degree of impairment of the central nervous system can also explain, at least in part, the NF1-reduced sweating. For instance, after sympathectomy, local sweating responses to pilocarpine becomes exacerbated, but it subsequently decreases and, in some cases, ceases completely ${ }^{22}$.

Decreased pharmacologically induced sweat production observed in type 1 diabetes and multiple sclerosis is an early sign of neuropathy, and it has been associated with reduced sympathetic nerve fiber density in the sweat glands ${ }^{10,23,24}$. In NF1, the development of large cutaneous and subcutaneous neurofibromas may cause dysfunctions in peripheral nerves leading to chronic pain, sensory loss, weakness or even palsy. Additionally, a symmetrical diffuse neuropathic process associated with thickening of peripheral nerves (called neurofibromatous neuropathy), can also cause distal sensory-motor symptoms ${ }^{1,14}$. Drouet et al. showed that, although asymptomatic in many cases, NF1 peripheral neuropathy constitutes a potentially severe complication as it is associated with increased morbidity related to the neuropathy itself, to spinal cord involvement and/or degeneration of a malignant peripheral nerve sheath tumor ${ }^{13}$. Nevertheless, until now, no studies have linked autonomic neuropathy to NF1 thermoregulatory capacity and heat intolerance.

As has been already described, there is a $10 \%$ reduction in aerobic capacity in NF1 patients ${ }^{5}$ and, the present NF1 
decrease in SR could possibly be related to the lower $\mathrm{VO}_{2 \max }$ and/or physical training levels, as is observed in healthy individuals $^{25,26}$. In a previous study applying the present method, healthy volunteers showed $20 \%$ reduced sweating response related to $20 \%$ reduced aerobic capacity ${ }^{9}$. Therefore, it seems unlikely that the $10 \%$ lower $\mathrm{VO}_{2 \max }$ previously reported in NF1 could exclusively explain the $35 \%$ to $65 \%$ reductions in NF1 SR observed here.

The NF1 volunteers also presented with less reduction in diastolic and mean arterial blood pressure in response to heat stress. During body hyperthermia states, physiological peripheral vasodilation mediated by neural and local (endothelial function) factors shifts part of the cardiac output to the skin surface for heat dissipation. Therefore, skin blood flow has a key role in normal thermoregulation and any disruption in its neural or/and local control may lead to impaired thermoregulation $^{27,28,29}$. It is possible that some degree of endothelial dysfunction observed in NF1 patients ${ }^{30}$ could contribute to the NF1-reduced vascular thermal response in the present study. It is interesting to note that, just like sweat production/secretion, vascular tone is directly regulated by the sympathetic nervous system, and therefore disturbances in the vasodilation response could be another indirect sign of neuropathy.
The possible mechanisms of lower responses of sweating and diastolic pressure control in NF1 may include sweat gland tissue dysplasia, lower cholinergic gland sensitivity, neuropathy and impairment in the vasodilation response. Therefore, the association of both lower sweat capacity and impaired vascular response is suggestive of an NF1 autonomic neuropathy, which should be confirmed by further histological and functional studies.

Finally, during passive heating, the NF1 group's internal temperature increased earlier and faster, reaching higher final values $\left(+0.6^{\circ} \mathrm{C}\right)$, leading to almost 10 times greater heat storage rate than controls. These findings are clear evidence of reduced thermoregulatory capacity caused by lower sweat capacity and impaired vascular response to heat stress in NF1. Nevertheless, considering the magnitude of heat storage observed, it should be safer to include NF1 as a predisposing factor to the development of heat illnesses during heat stress and/or intense exercise.

In conclusion, the NF1 volunteers presented with a markedly reduced thermoregulatory capacity, evidenced by lower sweating and vascular responses to pharmacological and passive heating stimuli compared to non-NF1 controls. Further large sample studies could support the present findings.

\section{References}

1. Ferner RE, Huson SM, Thomas N, Moss C, Willshaw H, Evans $D G$ et al. Guidelines for the diagnosis and management of individuals with neurofibromatosis 1.J Med Genet. 2007;44(2):81-8. doi:10.1136/jmg.2006.045906

2. Riccardi VM. Neurofibromatosis type 1 is a disorder of dysplasia: the importance of distinguishing features, consequences, and complications. Birth Defects Res A Clin Mol Teratol. 2010;88(1):9-14. doi:10.1002/bdra.20616

3. Rodrigues LOC, Batista PB, Goloni-Bertollo EM, Souza-Costa D, Eliam L, Eliam M et al. Neurofibromatoses: part 1 diagnosis and differential diagnosis. Arq Neuropsiquiatr. 2014;72(3):241-50. doi:10.1590/0004-282X20130241

4. Souza JF, Passos RL, Guedes AC, Rezende NA and Rodrigues LOC. Muscular force is reduced in neurofibromatosis type 1. J Musculoskelet Neuronal Interact. 2009;9(1):15-7.

5. Souza JF, Araújo CG, Rezende NA, Rodrigues LOC. Exercise capacity impairment in individuals with neurofibromatosis type 1. Am J Med Genet A. 2013;161A(2):393-5. doi:10.1002/ajmg.a.35729

6. Kenny GP, Yardley J, Brown C, Sigal RJ and Jay O. Heat stress in older individuals and patients with common chronic diseases. CMAJ 2010;182(10):1053-60. doi:10.1503/cmaj.081050

7. Gilsolfi CV, Mora F. The hot brain: survival, temperature and the human body. London: The Massachusetts Institute of Technology; 2000.

8. Shibasaki M, Wilson TE, Crandall CG. Neural control and mechanisms of eccrine sweating during heat stress and exercise. J Appl Physiol (1805). 2006;100(5):1692-701. doi:10.1152/japplphysiol.01124.2005

9. Madeira LG, Fonseca MA, Fonseca IA, Oliveira KP, Passos RL, Machado-Moreira CA et al. Sex-related differences in sweat gland cholinergic sensitivity exist irrespective of differences in aerobic capacity. Eur J Appl Physiol. 2010;109(1):93-100. doi:10.1007/s00421-009-1262-8

10. Davis SL, Wilson TE, White AT, Frohman EM. Thermoregulation in multiple sclerosis. J Appl Physiol (1985). 2010;109(5):1531-7. doi:10.1152/japplphysiol.00460.2010

11. Hoeldtke RD, Bryner KD, Horvath GG, Phares RW, Broy LF, Hobbs $\mathrm{GR}$ et al. Redistribution of sudomotor responses is an early sign of sympathetic dysfunction in type 1 diabetes. Diabetes 2001;50(2):436-43. doi:10.2337/diabetes.50.2.436

12. Rocha CM, Madeira LG, SÁ KR, Lopes LN, Albuquerque DP, Diniz LM et al. Diabetes mellitus tipo 1 na ausência de neuropatia autonômica não altera a taxa de sudorese no exercício. Rev Bras Med Esporte. 2009;15(1):23-6. doi:10.1590/S1517-86922009000100005

13. Drouet A, Wolkenstein P, Lefaucheur JP, Pinson S, Combemale $P$, Gherardi RK et al. Neurofibromatosis 1-associated neuropathies: a reappraisal. Brain. 2004;127(9):1993-2009. doi:10.1093/brain/awh234

14. Ferner RE, Hughes RAC, Hall SM, Upadhyaya M, Johnson MR. Neurofibromatous neuropathy in neurofibromatosis 1 (NF1). J Med Genet. 2004;41(11):837-41. doi:10.1136/jmg.2004.021683

15. Yerdelen D, Koc F, Durdu M, Karakas M. Electrophysiological findings in neurofibromatosis type 1. Neurol Sci. 2011;306(1-2):42-8. doi:10.1016/j.jns.2011.03.048

16. Kihara M, Opfer-Gehrking TL, Low PA. Comparison of directly stimulated with axon-reflex-mediated sudomotor responses in human subjects and in patients with diabetes. Muscle Nerve. 1993;16(6):655-60. doi:10.1002/mus.880160612

17. Chudnow RS, Wolfe GI, Sparagana SP, Delgado MR, Batchelor L, Roach ES. Abnormal sudomotor function in the hypomelanotic macules of tuberous sclerosis complex. J Child Neurol. 2000;15(8):529-32. doi:10.1177/088307380001500806 
18. Orozco-Covarrubias ML, Ridaura C, Tamayo-Sánchez L, DuránMckinster C, Ruiz-Maldonado R. [Tuberous sclerosis. Early diagnosis with autonomic nervous system responses in hypopigmented skin]. Rev Invest Clin. 1994;46(5):349-54. Spanish.

19. Davis SL, Wilson TE, Vener JM, Crandall CG, Petajan JH, White AT. Pilocarpine-induced sweat gland function in individuals with multiple sclerosis. J Appl Physiol (1985). 2005;98(5):1740-4. doi:10.1152/japplphysiol.00860.2004

20. Facer P, Mathur R, Pandya SS, Ladiwala U, Singhal BS, Anand P. Correlation of quantitative tests of nerve and target organ dysfunction with skin immunohistology in leprosy. Brain. 1998;121(12):2239-47. doi:10.1093/brain/121.12.2239

21. Randall WC, Kimura KK. The pharmacology of sweating. Pharmacol Rev. 1955;7(3):365-97.

22. Kuno Y. Human perspiration. Springfield: Charles C. Thomas; 1956.

23. Maselli RA, Jaspan JB, Soliven BC, Green AJ, Spire JP, Arnason BG. Comparison of sympathetic skin response with quantitative sudomotor axon reflex test in diabetic neuropathy. Muscle Nerve. 1989;12(5):420-3. doi:10.1002/mus.880120513

24. Gibbons $\mathrm{CH}$, Illigens BM, Wang N, Freeman R. Quantification of sweat gland innervation: a clinical-pathologic correlation. Neurology. 2009;72(17):1479-86. doi:10.1212/WNL.0b013e3181a2e8b8
25. Greenhaff PL, Clough PJ.. Predictors of sweat loss in man during prolonged exercise. Eur J Appl Physiol Occup Physiol. 1989;58(4):348-52. doi:10.1007/BF00643508

26. Buono MJ, White CS, Connolly KP. Cholinergic sensitivity of the eccrine sweat gland in trained and untrained men. J Dermatol Sci. 1992;4(1):33-7. doi:10.1016/0923-1811(92)90053-E

27. Kellogg DL Jr, Crandall CG, Liu Y, Charkoudian N, Johnson JM. Nitric oxide and cutaneous active vasodilation during heat stress in humans. J Appl Physiol (1985). 1998;85(3):824-9.

28. Charkoudian N. Skin blood flow in adult human thermoregulation: how it works, when it does not, and why. Mayo Clin Proc. 2003;78(5):603-12. doi:10.4065/78.5.603

29. Bruning RS, Santhanam L, Stanhewicz AE, Smith CJ, Berkowitz DE, Kenney WL et al. Endothelial nitric oxide synthase mediates cutaneous vasodilation during local heating and is attenuated in middle-aged human skin. J Appl Physiol (1985). 2012;112(12):2019-26. doi:10.1152/japplphysiol.01354.2011

30. Rodrigues LO, Rodrigues LO, Castro LL, Rezende NA, Ribeiro ALP. Non-invasive endothelial function assessment in patients with neurofibromatosis type 1: a cross-sectional study. BMC Cardiovasc Disord. 2013;13(1):18. doi:10.1186/1471-2261-13-18 